\title{
Transformações nas relações de trabalho e na política pública
}

\author{
Maria Cristina Cacciamali ${ }^{22}$
}

$\mathrm{R}_{\mathrm{a}}^{\mathrm{in}}$ icardo pontuou bem uma questão que muitas vezes nos confunde hoje, igualar o trabalho ao trabalhador - o trabalhador como uma categoria bem definida em um determinado período histórico e que nós associamos diretamente ao trabalhador fordista. Esse tipo de trabalhador fordista, de fato, está em fase de forte enxugamento numérico, mesmo com as modificações provocadas pelo toyotismo.

O trabalho, por outro lado, visto nas suas diferentes inserções e dimensões, não está no fim, até porque sua diminuição apenas pode ocorrer quando a organização social for distinta, quando as pessoas possam trabalhar menos no mercado e possam apropriar-se de renda através de outras formas.

\section{Isso é possível?}

Eu não creio em futurologia, mas há um dado muito claro: estamos em um momento histórico no qual a produtividade está aumentando fortemente e verificamos que, para sustentar a vida material da humanidade, o número necessário de pessoas é menor. Nunca houve um momento histórico em que se precisou de tão poucas pessoas para suprir tantos bens materiais. Entretanto, os resultados materiais ou imateriais dessa produção só poderão ser apropriados pelas pessoas caso sejam criados outros mecanismos, outras instituições, que não apenas o mercado para a distribuição de renda.

Muitos são os bens, que para serem usufruídos, não necessitariam obrigatoriamente serem consumidos através do mercado: a cultura, o lazer, o conhecimento e assim por diante. Então, a configuração do trabalho e da renda na sociedade do futuro vai depender das forças políticas, vai depender de como cada um de nós, inseridos em diferentes grupos, iremos nos postar diante dessa questão, que tipo de demandas políticas serão feitas no sentido de formatar e dar uma resposta a esse desafio.

No âmbito presente, estamos numa situação em que o fenômeno mais relevante é o desemprego. O desemprego hoje é global. Até dois anos atrás, a região asiática ainda apresentava taxas bastante satisfatórias de crescimento do emprego, posteriormente com a crise que se espalhou por aqueles países como um estopim, o desemprego explodiu por toda parte. O desemprego, na realidade, apenas é a ponta do iceberg de uma mudança muito forte, como Antunes apontou, diz respeito ao trabalhador (trabalhador fordista) e a essa transição do que será o trabalho. Por quê? Porque as pessoas de uma forma ou de outra têm que sobreviver e não há mecanismos alternativos ao mercado de trabalho.

O sistema de seguridade e proteção social, consolidado no pós-guerra, principalmente na Europa, foi uma instituição adequada ao modelo anterior - fordista. Ele se inicia no final do século passado, começa a se espalhar por alguns países no início deste século, entre os anos 20 e 30, e se torna um modelo muito completo e sofisticado, principalmente na Europa, após a segunda grande guerra. Esse sistema de proteção social deve ser modificado para atender as circunstâncias contemporâneas, principalmente nos países latino-americanos.

No caso europeu, há uma opção muito clara e um compromisso social sério com relação à manutenção da seguridade social: tentar fazer com que a Europa realize a transição deste momento de ruptura histórica através do trinômio alta tecnologia, educação e

${ }^{22}$ Professora da Faculdade de Economia, Administração e Contabilidade da Universidade de São Paulo. 
qualificação intensas, o que lhe provocará uma inserção muito favorável nos mercados mundiais. Então, essas metas fazem com que a sociedade persista na manutenção desse modelo de proteção social e procure aprimorá-lo.

Mas, nos países em que não se construiu esse tipo de ação e de consciência, objetivos ou metas tão fortes, como no caso europeu, nunca se consolidou da mesma maneira a proteção social e, portanto, as crises fiscais dos respectivos estados fazem com que esse sistema de seguridade perca importância e vivamos um vácuo de ordenamento público, nesta matéria.

Faço essa ponte para chegar ao mercado informal. No caso brasileiro, essa rede de proteção social, institucional, governamental, pública (no sentido de governo, pois "público" não é obrigatoriamente governo, pode significar "coletivo") sempre foi para os mais pobres a rede familiar, a rede comunitária, a rede de vizinhança. Para os mais ricos, não, pois a aposentadoria e o sistema de saúde funcionavam razoavelmente bem, no passado, até os anos 80. O SUS, posteriormente, em 1988, estabeleceu-se de uma forma abrangente, mas nunca atingiu a universalidade.

A própria CLT, quando se estabeleceu, teve como alvo a população urbana que naquele momento representava cerca de $40 \%$ da população brasileira. A legislação trabalhista só foi estendida para o campo nos anos 70 , durante o regime militar. Se pensarmos sobre outros bens públicos, por exemplo, a educação, quando ela começa a ser mais abrangente? Durante o período Vargas, mas também essa extensão deu-se de uma forma bastante desigual, abrangendo mais as áreas urbanas do que as áreas rurais, em uma época na qual as áreas rurais eram predominantes.

Nosso passado tem uma característica que não pode ser valorizada, uma característica escravocrata. Sempre esquecemos disto, há pouco mais de cem anos esse regime findou, mas suas marcas não foram metabolizadas pela sociedade brasileira, nos deixou características de forte desigualdade econômica, de poder e a pouca abrangência de direitos universais, até porque o conceito de cidadania e de "direitos universais" nunca se estabeleceu com clareza na sociedade brasileira.

Quanto à informalidade, ela precede tudo isso. Nunca tivemos um modelo social abrangente, portanto, a maior parte da população brasileira sempre viveu dentro de processos informais. No final do século passado, por exemplo, nós tínhamos quatro legislações trabalhistas neste país. Uma para a mão-de-obra escrava, outra para a mão-de-obra liberta, outra para a mão-de-obra migrante e uma última para os trabalhadores independentes. Isso só para que se possa ter uma idéia, pois eu poderia discorrer muito a respeito desse assunto.

Durante o período entre as décadas de 30 e 50 e posteriormente entre as décadas de 50 e 70, com a industrialização crescente, nós tivemos uma migração intensa para o meio urbano, como todos vocês sabem. O Brasil é destaque internacional nessa transposição porque não foi fruto de uma ação pública, governamental. Durante o processo migratório para as áreas metropolitanas, o PIB do país crescia a taxas mirabolantes (7\% ao ano é a média de 50 a 80 e houve períodos em que o país cresceu a 13\%).

Os economistas gostam de falar em crescimento, porque o crescimento não resolve todos os problemas, mas ajuda bastante: quando a riqueza flui, quando a renda flui, quando as pessoas podem encontrar uma atividade, seja ela sob a forma assalariada ou sob qualquer outra forma, a situação social realmente torna-se mais favorável. Nesse período, a mão-deobra que vinha para as cidades passava a ter carteira assinada, o emprego sem carteira era pouco expressivo e o trabalho por conta própria representava cerca de $17 \%$ da PEA.

Esse período constituiu um significativo processo de assalariamento. Diga-se de passagem, esse assalariamento não teve contrapartida de organização sindical na mesma magnitude, porque passamos por um período de regime militar que bloqueou o florescimento 
dessa organização, embora, no início dos anos 80 , tenhamos tido uma eclosão sindical de bom nível e moderna.

Nesse período, a informalidade não era um problema grave. A pobreza era o grande problema, o trabalhador pobre, a degradação das áreas urbanas, pois o fluxo migratório era fantástico e não havia recursos para a infra-estrutura física, não havia planejamento para receber todas essas pessoas. Toda a política (que muda a partir dos anos 80 ) girava em torno de uma ação centralizada do Estado e do governo federal. Eram decisões tomadas de cima para baixo que nem sempre atendiam às necessidades específicas, das localidades ou das comunidades.

Nesse período percebeu-se que o setor informal representava um fenômeno permanente. Havia uma discussão teórica bastante longa, de quase dez anos, com relação ao fato desse trabalho por conta própria, centrado na própria família, esse pequeno empreendimento, esse negócio familiar ter ou não condições de sobreviver durante o processo de expansão do capital, questionava-se se essas atividades teriam a tendência a desaparecer ou se permaneceriam. O resultado dessa discussão foi a confirmação de que se tratava de um fenômeno permanente e que esses pequenos negócios, esses pequenos empreendimentos transformavam-se no bojo e juntamente com o próprio processo de acumulação.

Durante a crise dos anos 80 começa a surgir um fenômeno diferente. Surge o fenômeno que é o assalariamento sem carteira, em virtude do ajuste recessivo, e um crescimento do trabalho por conta própria e dos pequenos negócios. Além do mais, o início dos anos 80 caracteriza-se também por uma elevação da taxa de desemprego. Foi a primeira grande crise capitalista no país, a crise de 1981 a 1983.

Os anos 80 foram um período de elevada instabilidade. $O$ país não conseguiu fazer nenhum tipo de reestruturação qualquer que seja a dimensão analisada $E$ nós chegamos ao final desse período com problemas muito sérios no que se referia aos níveis de produtividade e, obviamente, poucos problemas em relação ao emprego. Exatamente porque as reformas e a reestruturação produtiva ainda eram muito lentas no país.

Foi nos anos 90 que o Brasil apresentou forte explosão de todos os problemas que não tinham sido atacados durante os anos 80 . Tivemos uma abertura comercial irrestrita e sem nenhum tipo de planejamento, um Estado que não conseguia mais responder às demandas sociais nem às do próprio funcionamento do aparelho do Estado. Tivemos problemas com relação à reestruturação produtiva e à modernização tecnológica, com isso a taxa de desemprego foi crescendo ao longo de todo o período.

Hoje estamos com $9 \%$ de desemprego, segundo a fonte oficial, e com $20 \%$, segundo o índice do Dieese (Departamento Intersindical de Estatísticas e Estudos Socioeconômicos). $\mathrm{Na}$ realidade, a taxa deve se situar mais próxima dos $20 \%$ do que dos $9 \%$, embora a taxa de $20 \%$ revele níveis de subemprego e não exatamente de desemprego. Mas, como eu disse, o desemprego não revela todo o problema.

Uma das características da reorganização da estrutura produtiva, como Antunes apontou muito bem, é uma horizontalização das cadeias produtivas e um processo de terceirização. Isso, ao meu juízo, não é setor informal, é um processo semelhante de mudanças de relações de trabalho, não o núcleo típico da informalidade, pois a maior parte dessas relações ainda se dão no âmbito de uma transformação tipicamente capitalista.

O fenômeno processo de informalidade se resumiria de duas maneiras. Primeiro, diz respeito àquele conjunto de pessoas que por opção ou por necessidade de sobrevivência (as duas coisas convivem no mercado) optam por negócios por conta própria, optam por uma mini-organização para poderem sobreviver. $\mathrm{O}$ outro aspecto da informalidade é toda essa reformatação legal e institucional que está ocorrendo nas relações de trabalho em todas as suas dimensões. Ou seja, hoje, no Brasil, nós temos mão-de-obra assalariada que trabalha 
com carteira, que trabalha sem carteira, que trabalha sob a forma de cooperativas, que trabalha sob a forma autônoma, que trabalha, enfim, sob as mais diferentes formas. Às vezes por tarefa, às vezes por empreitada, mas, mesmo assim, trata-se de mão-de-obra assalariada. Esse processo de reformatação das relações assalariadas também podem ser classificadas como um categoria do processo de informalidade ou processo de informalização. Na realidade, refere-se a todo um processo de reformatação das formas de inserção e das relações institucionais de trabalho.

Ao final, o que mais chama a atenção é que, hoje, quando olhamos para o mercado de trabalho, temos em torno de $40 \%$ da mão-de-obra que trabalha de forma assalariada e com carteira de trabalho. O restante trabalha sob outras formas, o que mostra a velocidade com que esse fenômeno está ocorrendo, essa reformatação profunda que está ocorrendo no mercado de trabalho. Alguns autores chamam isso de "desassalariamento". Eu chamaria de fim de um certo tipo de sociedade assalariada, pois podemos ter outros tipos de sociedades assalariadas. Aquela que conhecemos na segunda metade deste século realmente está se transformando muito.

Outro aspecto importante diz respeito ao próprio aparelho público do Estado: 40\% contribui e quase $60 \%$ não contribui com nada ou com muito pouco. Ou seja, como se pode querer que esse aparelho público funcione? Os direitos são universais, mas são mantidos com a contribuição de $40 \%$. A falência do sistema está exatamente aí. É uma questão para se repensar.

Mais um aspecto importante é que a maior parte das pessoas, mesmo as assalariadas, trabalham cada vez mais no setor terciário, no setor de serviços, e menos nas fábricas, na indústria de transformação. Isso traz fortes modificações, também, na própria organização política e na consolidação de interesses setoriais. Hoje, os interesses são altamente fragmentados, inclusive porque o trabalho é altamente fragmentado. É uma questão sobre a qual devemos pensar.

E por último, eu gostaria de concluir (eu não apresentei todas as características do mercado informal... quem sabe no debate a gente possa falar um pouco mais...) falando da necessidade de mudança da política pública dentro desse quadro. Muitas pessoas acreditam que o Estado está se desfortalecendo e, de certa maneira, dependendo da ótica, até está. $\mathrm{Na}$ realidade, a meta não é o desfortalecimento do Estado, mas sim a mudança da atuação do Estado para uma maneira muito mais descentralizada, muito mais localizada e com muito mais poder normativo. A grande questão passa a ser o poder normativo e não o tamanho do Estado. Isso é bastante importante, pois toda essa reformatação do trabalho vai passar muito pelas localidades, por territórios específicos e nós precisamos estar atentos para que não haja mais deterioração durante um período de transição como este, já que a tendência é de deterioração mesmo, com relação aos níveis de saúde, salário, de responsabilidades do aparelho público e assim por diante.

\section{É isso. Muito obrigada.}

